\title{
A PROPOSTA DO PATRIOTISMO CONSTITUCIONAL EM HABERMAS E MÜLLER COMO SOLUÇÃO DE COESÃO SOCIAL EM SOCIEDADES MULTICULTURAIS E DEMOCRÁTICAS
}

\author{
THE PROPOSAL OF CONSTITUTIONAL PATRIOTISM IN HABERMAS AND \\ MÜLLER AS A SOLUTION OF SOCIAL COHESION IN MULTICULTURAL AND \\ DEMOCRATIC SOCIETIES
}

\begin{abstract}
LA PROPUESTA DE PATRIOTISMO CONSTITUCIONAL EN HABERMAS Y MÜLLER COMO SOLUCIÓN DE COHESIÓN SOCIAL EN SOCIEDADES MULTICULTURALES Y DEMOCRÁTICAS
\end{abstract}

\author{
JOSEMAR SOARES \\ https://orcid.org/0000-0001-6412-4094 / http://lattes.cnpq.br/8022461281177382 / jsoares@univali.br
}

\begin{abstract}
RESUMO
O objetivo do presente artigo é apresentar a dialética do reconhecimento em visão hegeliana como condição epistemológica para efetivação da proposta de patriotismo constitucional, a partir das concepções de Habermas e Müller, tendo em vista realização de coesão social em sociedades multiculturais e democráticas. A pesquisa parte da premissa de que a fragmentação interna nas sociedades democráticas contemporâneas, sobretudo decorrente das migrações transnacionais, dificulta a unidade e a coesão a partir das ideias de etnia, nação, entre outras. Desse modo o patriotismo constitucional busca oferecer solução com a unidade sendo estabelecida pelo respeito à Constituição, e não mais por uma visão nacionalista. O constitucionalismo é capaz de tanto garantir a coesão social como a proteção dos direitos básicos e liberdades individuais dos membros da comunidade. $\mathrm{O}$ artigo discorre ainda sobre a dialética do reconhecimento, argumentando que esta é condição epistemológica para o patriotismo constitucional. A pesquisa utiliza método indutivo, por meio de abordagem bibliográfica.
\end{abstract}

Palavras-chave: Constitucionalismo; Multiculturalismo; Patriotismo Constitucional; Reconhecimento.

\begin{abstract}
The aim of this paper is to present a dialectic of recognition in the Hegelian view as an epistemological condition for the realization of the proposal of constitutional patriotism, based on the conceptions of Habermas and Müller, with a view to achieving social cohesion in multicultural and democratic societies. One research starts from the premise that internal fragmentation in contemporary democratic societies, mainly due to transnational migrations, hinders unity and cohesion from the ideas of ethnicity, nation, and others. In this way or constitutional patriotism seeks to offer solution with unity being considered by respect for the Constitution, and no longer by a nationalist view. Constitutionalism is capable of guaranteeing social cohesion as a protection of the basic rights and individual freedoms of community members. The article also discusses the dialectic of recognition, arguing that this is an epistemological condition for constitutional patriotism. A research uses the inductive method, through bibliographical approach.
\end{abstract}

Keywords: Constitutionalism; Constitutional Patriotism; Multiculturalism; Recognition.

\section{RESUMEN}

El objetivo de este trabajo es presentar la dialéctica del reconocimiento en la visión hegeliana como una condición epistemológica para la implementación de la propuesta de patriotismo constitucional, basada en las concepciones de Habermas y Müller, con el objetivo de lograr la cohesión social en sociedades multiculturales y democráticas. La investigación parte de la premisa de que la fragmentación interna en las sociedades democráticas contemporáneas, principalmente debido a las migraciones transnacionales, dificulta la unidad y la cohesión en función de las ideas de 
etnicidad, nación, entre otros. De esta manera, el patriotismo constitucional busca ofrecer una solución con la unidad establecida por el respeto a la Constitución, y ya no por una visión nacionalista. El constitucionalismo es capaz de garantizar la cohesión social y proteger los derechos básicos y las libertades individuales de los miembros de la comunidad. El artículo también discute la dialéctica del reconocimiento, argumentando que esta es una condición epistemológica para el patriotismo constitucional. La investigación utiliza el método inductivo, a través del enfoque bibliográfico.

Palabras clave: Constitucionalismo; Multiculturalismo; Patriotismo Constitucional; Reconocimiento.

\section{SUMÁRIO}

INTRODUÇAO; 1 MULTICULTURALISMO; 2 O PATRIOTISMO CONSTITUCIONAL; 3 RECONHECIMENTO E PATRIOTISMO CONSTITUCIONAL; CONCLUSÃO; REFERÊNCIAS.

\section{INTRODUÇÃO}

O objetivo deste artigo é apresentar a dialética do reconhecimento em visão hegeliana como condição epistemológica para efetivação da proposta de patriotismo constitucional, a partir das concepções de Habermas e Müller, tendo em vista realização de coesão social em sociedades multiculturais e democráticas.

Como problema de pesquisa tem-se, portanto: pode a dialética do reconhecimento, em matriz hegeliana, ser condição epistemológica de efetividade para a proposta de patriotismo constitucional, tendo em vista este se tornar instrumento necessário para realização da coesão social em sociedades multiculturais e democráticas?

A pesquisa parte do pressuposto de que em sociedades multiculturais democráticas na contemporaneidade a coesão social é difícil de ser atingida a partir de critérios tradicionais como etnia, família, religião e inclusive nação, tendo em vista a profunda diversidade (social, moral, ideológica, étnica, etc.) existente no interior de tais sociedades. Na filosofia moderna Hegel já salientara que a coesão social é necessária porque impede a fragmentação de colocar em risco a própria integridade da sociedade e do Estado.

Por coesão social, seguindo a abordagem de Habermas e Werner, entende-se aqui a disposição de que os membros de determinada comunidade possuem de agir em prol da manutenção da estabilidade das regras e instituições, reconhecendo-se como partes de uma totalidade. Seguindo a fórmula hegeliana a sociedade precisa da ideia de 'Nós', de um 'Eu' que se visualiza no 'Nós', como parte de uma sociedade organizada visando um mesmo escopo.

Desde a modernidade a coesão social parecia ser satisfatoriamente realizada a partir de concepções como etnia, religião, valores tradicionais, nação, entre outras. A nacionalidade, inclusive, provavelmente é o último critério a surgir, justamente para convergir membros 
provindos de identidades regionais distintas a uma unidade nacional. Observa-se, por exemplo, a dificuldade de países como Espanha e Itália de manterem uma unidade nacional quando mesmo internamente apresentam profundas distinções regionais.

Mas mesmo a nacionalidade sofreu pesado golpe com as experiências totalitárias na II Guerra Mundial, pois desde então a efervescência nacionalista pode ser confundida com disposição à xenofobia. A questão se torna paradigmática na experiência germânica do pós Guerra: a partir de qual critério pode a Alemanha erguer uma unidade e coesão social sem recorrer ao nacionalismo?

A resposta, que começa a se desenhar em Sternberg influenciado por Jaspers, mas adquire contornos mais sólidos em Habermas e Müller, parece passar pela valorização do constitucionalismo, na medida em que os princípios e valores da Constituição buscariam reproduzir não o consenso de determinado grupo ou etnia, mas da totalidade (formada a partir de uma pluralidade heterogênea) de pessoas habitantes de determinado território sintetizado como Estado-nação.

Aqui surge a ideia de um patriotismo constitucional. A expressão 'patriotismo' talvez não seja muito evidente, mas ela é empregada pelos filósofos estudados justamente para apontar a necessidade de se respeitar e cultivar a Constituição, pois ali se encontra o pilar que pode sustentar uma sociedade multicultural e democrática.

Ainda assim a mera formalização de uma Constituição não é suficiente para garantir a coesão social. É necessário o 'patriotismo', isto é, o estímulo constante aos indivíduos se reconhecerem na Constituição. Isto não significa, evidentemente, que todos devem concordar com cada tópico da Constituição, mas na disposição de se reconhecer na Constituição, de entender esta como resultado das dialéticas internas historicamente falando em determinada sociedade. Pode-se argumentar no sentido de alterar e aperfeiçoar elementos da Constituição, mas não o da sua supremacia enquanto mantenedora ou estimuladora da coesão social.

E este processo passa por aquilo que Hegel define como dialética do reconhecimento, do Eu sair de si e reconhecer o Outro a partir do Nós. Um Nós que se expressa nas normas e instituições, em especial na Constituição. Sem a dialética do reconhecimento permeando o patriotismo constitucional o constitucionalismo tende a ser manifestação de direito abstrato, que a sociedade enxerga como imposição, mas jamais como reflexo orgânico de sua disposição de vontade.

Este processo dialético é possível na medida em que os indivíduos começam a se efetivarem enquanto membros de uma comunidade, ou mitglied, na terminologia hegeliana, 
como partes que se responsabilizam pelo funcionamento das instituições, pois exercitam esse dever como pflicht, como uma obrigação que decorre de suas próprias funções enquanto membros de uma comunidade, em função da Constituição, expressão orgânica do Todo a partir das dialéticas históricas vivenciadas.

Isto é possível porque, seguindo a trilha de Buber, o diálogo medeia a relação Eu-Tu, no sentido de que o Eu se abre ao outro e neste processo compartilha valores, experiências, mediando uma relação ética de responsabilidade perante a comunidade. 0 ser humano é inteligente, capaz de diálogo responsável e ético na dialética Eu-Tu. ${ }^{1}$

Em primeiro momento este artigo explora a ideia de multiculturalismo nas sociedades contemporâneas. A segunda parte apresenta a noção de patriotismo constitucional, conforme Sternberg, Habermas e Müller, como necessário instrumento de coesão social em sociedades multiculturais e democráticas. A terceira parte traz a dialética do reconhecimento em perspectiva hegeliana como condição epistemológica para efetivação do patriotismo constitucional.

Quanto à metodologia, foi utilizada a base lógica indutiva, por meio da pesquisa bibliográfica a ser utilizada no desenvolvimento da pesquisa, o método cartesiano, quanto à coleta de dados, e, no relatório final, o método indutivo com as técnicas do referente, da categoria, dos conceitos operacionais, da pesquisas bibliográfica e do fichamento. ${ }^{2}$ As obras Fenomenologia do Espírito e Filosofia do Direito, de Hegel, são citadas nos originais em alemão, sendo que as traduções utilizadas são as de Paulo Meneses ${ }^{3}$, das respectivas edições brasileiras referenciadas.

\section{MULTICULTURALISMO}

Uma das principais problemáticas enfrentadas pelo constitucionalismo contemporâneo ${ }^{4}$ é aquela do fenômeno do multiculturalismo, sobretudo advindo das migrações transnacionais.

\footnotetext{
${ }_{1}^{1}$ BUBER, Martin. Eu e Tu. São Paulo: Centauro, 2001.

2 PASOLD, Cesar Luiz. Metodologia da pesquisa jurídica: teoria e prática. Florianópolis: Conceito Editorial. 2015.

3 HEGEL, G. W. F. Fenomenologia do Espírito. Tradução de Paulo Meneses. Petrópolis: Vozes, 2005; HEGEL. G W. F. Filosofia do Direito. Tradução de Paulo Meneses. São Leopoldo: Ed. da UNISINOS, 2010.

${ }^{4}$ Para um estudo aprofundado sobre os desafios do constitucionalismo contemporâneo ver CRUZ, Paulo Márcio; PASOLD, César Luiz; FERRER, Gabriel Real. Reflexões sobre o futuro do Estado constitucional moderno, Revista Brasileira de Políticas Públicas, v. 6, p. 22-38, 2016.
} 
ISSN 1981-3694

(DOI): $10.5902 / 1981369441312$

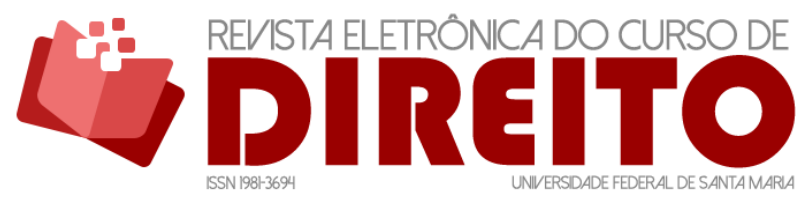

A PROPOSTA DO PATRIOTISMO CONSTITUCIONAL EM HABERMAS E MÜLLER COMO SOLUÇÃO DE COESÃO SOCIAL EM SOCIEDADES MULTICULTURAIS E DEMOCRÁTICAS

A questão do multiculturalismo, apresentada enquanto fenômeno marcante - sobretudo nas sociedades ocidentais contemporâneas, as quais revelam elevado grau de diferenciação étnica, cultural, religiosa e moral dentro de sua população-, resulta, entre outros fatores, das crescentes ondas de migrações transnacionais. ${ }^{5}$

Lanzillo ${ }^{6}$ lembra que a dificuldade de se enfrentar tal problemática está no fato de que o multiculturalismo vem sendo, nas últimas décadas, tanto defendido como bandeira ideológica a ser perseguida, no sentido de ser a sociedade multicultural o modelo ideal de comunidade futura para todos os povos e Estados, como também vista agressivamente na perspectiva de ser uma ameaça da integridade nacional e dos costumes que tradicionalmente caracterizavam cada povo. ${ }^{7}$ Para alguns o multiculturalismo representaria um avanço democrático, para outros a causa de tantos problemas sociais, econômicos e morais das sociedades contemporâneas, do aumento de criminalidade à oferta de emprego, passando pelas despesas previdenciárias e

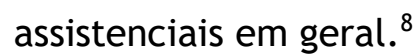

A questão parece girar em torno de ser a favor ou contra certa ideologia universalística, a qual defenderia a progressiva integração das diversidades ao redor do planeta. Por outro lado, não se pode ignorar a crescente atmosfera do cosmopolitismo, a qual, nas palavras de Benhabib, parece traduzir a sensação de que o mundo inteiro é apenas uma polis, formada a partir de complexas relações transnacionais. E estas relações transnacionais incluem tanto corporações empresariais como grupos terroristas, ou seja, a potencialidade de vínculos hoje não serem apenas locais ou nacionais, mas transnacionais, provoca o aumento da percepção de que cada vez mais cada indivíduo passa a integrar uma sociedade cosmopolita, ainda que habite este ou aquele Estado nacional. ${ }^{9}$

Tanto o multiculturalismo como as migrações não são fenômenos exclusivos da contemporaneidade, pois o deslocamento de indivíduos, grupos e povos se verifica desde o início

\footnotetext{
${ }^{5}$ Para aprofundamentos da questão das migrações transnacionais sugere-se: PILAU SOBRINHO, Liton Lanes; SIRIANNI, Guido; PIFFER, Carla. Migrações transnacionais e multiculturalismo: um desafio para a União Europeia, Revista Novos Estudos Jurídicos, v. 19, n. 4, 2014; LOCCHI, Maria Chiara. La questione del riconoscimento giuridico delle differenze culturali nelle società pluraliste: alcune considerazioni a partire dalla giurisprudenza sui rom della Corte Europea dei diritti dell'uomo, Revista Novos Estudos Jurídicos, v. 20, n.1, 2015.

${ }^{6}$ LANZILLO, Maria Laura. II multiculturalismo. Bari: Laterza, 2005. p. VIII-IX.

${ }^{7}$ GOZZI, Gustavo. Diritti e Civiltà. Bologna: Il Mulino, 2010. p. 326-328.

8 COMIN, Lidiane Cássia; PAULI, Jandir. The meaning of work, organizational socialization and work context: the perspective of migrant workers, Revista de Administração Mackenzie, v. 19, 2018; TRUZZI, Oswaldo; MONSMA, Karl. Sociologia das migrações: entre a compreensão do passado e os desafios do presente, Revista Sociologias, ano 20, n. 49, 2018.

9 BENHABIB, Seyla. The rights of others: aliens, residents and citizens. Cambridge: Cambridge University Press, 2004. p. 174-175.
} 
ISSN 1981-3694

(DOI): $10.5902 / 1981369441312$

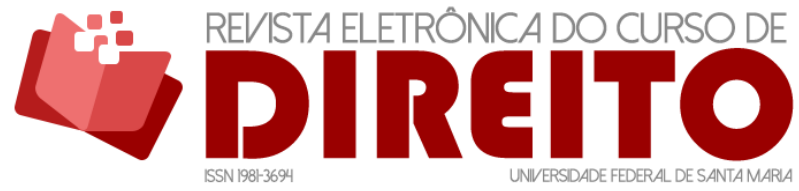

A PROPOSTA DO PATRIOTISMO CONSTITUCIONAL EM HABERMAS E MÜLLER COMO SOLUÇÃO DE COESÃO SOCIAL EM SOCIEDADES MULTICULTURAIS E DEMOCRÁTICAS

dos registros históricos. São conhecidas as profundas diversidades linguísticas e culturais tanto do mundo mesopotâmico como romano, apenas para citar exemplos conhecidos. A própria história da origem e formação dos Estados nacionais na modernidade depende do entendimento de como estes se estabeleceram a partir da necessidade de criar uma unidade nacional em territórios marcados pela pluralidade étnica, linguística, cultural e, por vezes, inclusive religiosa. ${ }^{10}$

No entanto, o que demarca como diferenciado o período contemporâneo é o alcance de tal multiculturalismo que facilmente se alastra para além de regiões específicas, espalhando-se sempre mais pelo próprio globo, de tal modo que a migração transnacional hoje não parece ser mais um fenômeno de deslocamentos isolados de pessoas, mas um fluxo permanente de transitoriedade das fronteiras nacionais. Ainda que muitas migrações sejam motivadas por catástrofes ambientais, crises humanitárias e problemas bélicos, o fluxo de pessoas abandonando lugares de nascimento para tentarem conduzir a vida em outros espaços é sempre mais presente. Sempre que uma pessoa ou grupo migra, cria-se um vínculo entre o local de origem e o de destinação, de modo que a migração de pessoas é sempre também migração econômica, cultural, moral, religiosa, social, e inclusive com implicações jurídicas. ${ }^{11}$

A partir do entendimento que este fluxo será cada vez maior, Benhabib lembra que este fenômeno se apresenta como principal desafio para a consciência moral das democracias liberais contemporâneas, vez que a aceitação do outro, portador de cultura e valores distintos, atinge o núcleo da formulação democrática liberal enquanto pretensão de modelo político e de convivência universal. ${ }^{12}$

Isto é, na medida em que a diversidade conduz inevitavelmente a choque de visões de mundo, a discordância quanto a estilos de vida - o que perpassa cada esfera da vida, daquela econômica à jurídica, passando pela religiosa, cultural, social em geral-, a capacidade das sociedades democráticas de aceitarem e reconhecerem o outro e a efetuarem dialéticas nas quais ambos passem a se verem como um 'nós' que integra determinado Estado ou nação é condição indispensável para a estabilidade e integração atual e futura das comunidades

\footnotetext{
${ }^{10}$ Ver, por exemplo, as obras de Anthony Smith e Hermann Heller. SMITH, Anthony. The ethnic origins of Nations. New Jersey: Wiley-Blackwell, 1991; HELLER, Hermann. Teoria do Estado. São Paulo: Mestre Jou, 1968.

11 AMBROSINI, Maurizio. Un'altra globalizzazione: la sfida delle migrazioni trasnazionali. Bologna: Il Mulino, 2009. p. 43-45.

12 BENHABIB, Seyla. The rights of others: aliens, residents and citizens. p. 177-179.
} 
ISSN 1981-3694

(DOI): $10.5902 / 1981369441312$

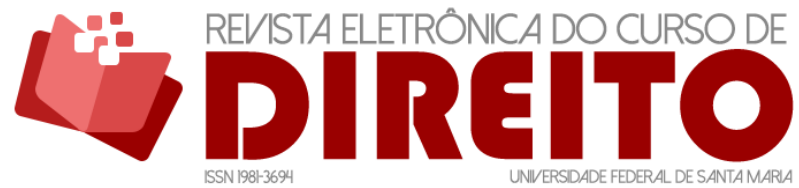

A PROPOSTA DO PATRIOTISMO CONSTITUCIONAL EM HABERMAS E MÜLLER COMO SOLUÇÃO DE COESÃO SOCIAL EM SOCIEDADES MULTICULTURAIS E DEMOCRÁTICAS

marcadas por crescente multiculturalismo. ${ }^{13}$ É a partir daqui que se pode vislumbrar ou a formação de uma consciência moral para além das diversidades ou a permanência de conflitos conduzindo a um progressivo dilaceramento interno de tais sociedades. ${ }^{14}$ Esta realidade é desafio para o constitucionalismo ${ }^{15}$ contemporâneo, que precisa lidar com maior amplitude de diversidades internas na população abrangida. Constitucionalismo lida com multiplicidade e diversidade. ${ }^{16}$

Kymlicka sintetiza o desafio do multiculturalismo como 0 de promover 0 reconhecimento das identidades étnicas e culturais das minorias dentro das comunidades políticas, realizando um processo de integração que respeite as diferenças culturais. ${ }^{17}$

Mas para o autor as democracias liberais contemporâneas podem lidar satisfatoriamente com esta demanda, pois o reconhecimento dos direitos de grupos minoritários seria coerente com os princípios básicos da liberdade individual e da justiça social. 0 reconhecimento dos grupos minoritários de terem liberdade para viver seus próprios valores e estilos de vida se enquadra em uma condição democrática liberal, desde que esta tolerância não coloque em risco a integridade do grupo majoritário e de outros grupos minoritários. Isto é, Kymlicka tem noção de que a liberdade aos grupos minoritários não pode ser ilimitada, porque isto levaria à possibilidade de culto a valores que agrediriam outros grupos e os próprios pilares constitucionais. Trata-se de um raciocínio liberal que já encontra seus fundamentos no pensamento de Locke, do liberalismo baseando-se na tolerância, mas numa tolerância limitada, porque do contrário permitiria a disseminação de ideologias e pensamentos que poderiam ameaçar a própria ideia de tolerância. ${ }^{18}$

No entanto, esta concessão pode ser não mais que uma tentativa de acomodar grupos ideologicamente muito distintos no mesmo território, no sentido de tolerar grupos minoritários que em si mesmos seriam contrários à ideia de uma democracia liberal, mas insuficiente

\footnotetext{
${ }^{13}$ Para uma discussão sobre estabilidade como princípio a ser perseguido em sociedades multiculturais ver NORMAN, Wayne. Justice and Stability in multinational societies. In: GAGNON, Alain; TULLY, James (Orgs.). Multinational Democracies. Cambridge: Cambridge University Press, 2001.

${ }^{14}$ Para uma discussão da democracia enquanto tentativa de solucionar conflitos internos ver ROSANVALLON, Pierre. Counter-Democracy: Politics in a age of Distrust. Cambridge: Cambridge University Press, 2008. p. 3-5.

${ }^{15}$ Sobre o projeto de constitucionalismo e suas implicações contemporâneas ver CADEMARTORI, Sergio; CADEMARTORI, Daniela. Da tradição ocidental de constitucionalismo ao novo constitucionalismo latinoamericano: análise das garantias constitucionais, Revista Novos Estudos Jurídicos, v. 19, n.3, p. 10141044.

${ }^{16}$ Ver TULLY, James. Strange multiplicty: constitutionalism in a age of diversity. Cambridge: Cambridge University Press, 1995.

${ }^{17}$ KYMLICKA, Will. Multicultural citizenship. Oxford: Oxford Press, 1995. p. 10.

18 Ibidem, p. 151-154.
} 
ISSN 1981-3694

(DOI): $10.5902 / 1981369441312$

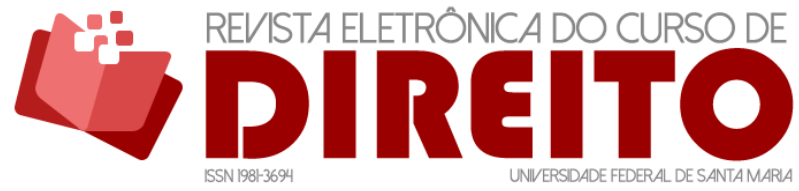

A PROPOSTA DO PATRIOTISMO CONSTITUCIONAL EM HABERMAS E MÜLLER COMO SOLUÇÃO DE COESÃO SOCIAL EM SOCIEDADES MULTICULTURAIS E DEMOCRÁTICAS

enquanto projeto de integração ética em uma dada comunidade. A tolerância é fundamental enquanto ato de respeito ao próximo dentro de uma comunidade, mas o desenvolvimento social exige mais do que simples tolerância, exige decisivo engajamento dos vários grupos nas instituições políticas, e aqui o problema persiste, porque embora um grupo minoritário seja respeitado em seus valores, pode não se sentir à vontade para tentar participar da arena política, vez que não compreende ou concorda com todos os valores defendidos pelo grupo majoritário. ${ }^{19}$

Este processo, contudo, exige mais do que apenas tolerância ao outro. A convivência funcional e politicamente inteligente passa pelo respeito ao outro como portador de dignidade, como participante de uma comunidade que busca aprimorar a si mesma, o que exige capacidade de gerenciar conflitos e dialéticas. Para grupos diferentes ideologicamente, culturalmente ou etnicamente se envolverem em harmonia visando o bem estar coletivo é necessário que reconheçam-se uns nos outros enquanto indivíduos e grupos humanamente dignos e politicamente responsáveis perante a comunidade. Retoma aqui a importância de se afirmar a dignidade enquanto condição de respeito e reconhecimento ao outro a partir de uma Constituição. ${ }^{20}$

Como criar, consolidar e manter coesão social em sociedades multiculturais e democráticas? De um lado é necessário criar unidade entre os membros, e de outro resguardar as liberdades individuais e direitos básicos das pessoas. Sem recorrer a valores tradicionais, nacionais, étnicos, religiosos, como criar esta unidade que abre espaço à diversidade? Esta é a proposta de patriotismo constitucional, sobretudo em Habermas e Müller, conforme próximo tópico.

No próximo tópico adentra-se a questão do patriotismo constitucional como caminho para coesão social em sociedades multiculturais e democráticas.

\section{O PATRIOTISMO CONSTITUCIONAL}

A própria expressão 'patriotismo constitucional', relembra Müller, em primeiro momento parece uma contradição, pois a ideia de patriotismo tende a reclamar atitude de sacrifício individual em benefício dos interesses comunitários, enquanto o constitucionalismo

\footnotetext{
${ }^{19}$ KYMLICKA, Will. Multicultural citizenship. Oxford: Oxford Press, 1995. p. 151-154.

20 Ibidem.
} 
ISSN 1981-3694

(DOI): $10.5902 / 1981369441312$

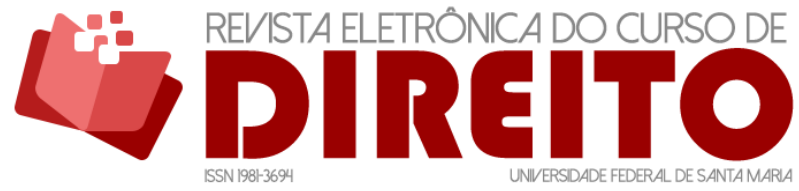

A PROPOSTA DO PATRIOTISMO CONSTITUCIONAL EM HABERMAS E MÜLLER COMO SOLUÇÃO DE COESÃO SOCIAL EM SOCIEDADES MULTICULTURAIS E DEMOCRÁTICAS

surge como construção histórica de alargamento de direitos básicos e liberdades individuais ao cidadão. Esta percepção não é aleatória, pois de fato o patriotismo constitucional busca fornecer subsídios para uma nova forma de coesão social, em tempos pós-modernos, sem perder a dimensão da proteção das liberdades individuais. Não é simples construir coesão social em período nos quais valores antes vistos como quase sagrados, tais como a religião, a nação e o Estado, parecem enfraquecidos ou ao menos incapazes de garantir harmonia interna diante do crescente multiculturalismo e fragmentação moral. ${ }^{21}$

Ademais, não é sem razão que a noção de patriotismo constitucional apresenta suas raízes no pensamento jusfilosófico e político alemão do pós-Guerra, em especial com Sternberg e Habermas, embora a partir de linhas discursivas distintas. ${ }^{22}$

Sternberg preocupa-se, sobretudo, com a necessidade de dar coesão à sociedade alemã da segunda metade do século XX sem retomar um patriotismo nacionalista, ainda demasiado marcado pelas experiências totalitárias da II Guerra Mundial. Portanto, o problema estava em garantir vínculos de pertencimento dos cidadãos ao Estado sem que tais vínculos passassem por uma espécie de orgulho étnico, racial ou mesmo nacional, até porque com as crescentes ondas migratórias e fortalecimentos de uma economia globalizada o sentido étnico-nacional não seria capaz de garantir unidade a uma nova Alemanha, que buscava se distanciar daquele espírito germanista que marcou tantos movimentos dos dois séculos anteriores. É neste aspecto que a Constituição e os valores constitucionais, na visão de Sternberg, poderiam facilitar o surgimento de um novo patriotismo. ${ }^{23}$

Já a proposta de Habermas não está tão centrada na realidade específica alemã, mas mais em garantir uma coesão social em sociedades pós-tradicionais, ou pós-modernas, nas quais a religião e o pertencimento a grupos étnicos ou nacionais parecem incapazes de garantir coesão, diante da ampliação da fragmentação de estios de vida em sociedades multiculturais. Desse modo, as visões específicas sobre como deveria se organizar a sociedade (perspectivas religiosas, familiares, étnicas, nacionais, etc.) seriam subsumidas por critérios universais e universalizantes, como garantia de direitos civis básicos e liberdades individuais a cada cidadão,

\footnotetext{
${ }^{21}$ MÜLLER, Jan-Werner. Constitutional Patriotism. New Jersey: Princeton University Press, 2007. p. 1-3.

22 Ibidem. p. 18-20.

${ }^{23}$ Sternberg foi aluno do filósofo Karl Jaspers, que lidou bastante com a questão da culpa alemã em sua obra. Culpa, que para Jaspers, era não apenas política e jurídica, mas também moral e metafísica. Daí se extrai que a noção de patriotismo constitucional de Sternberg extrai suas raízes das reflexões jasperianas sobre a culpa alemã no século XX e a necessidade sua superação a partir de uma 'responsabilidade coletiva'.
} 
ISSN 1981-3694

(DOI): $10.5902 / 1981369441312$

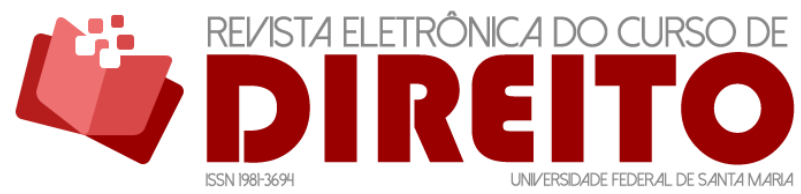

A PROPOSTA DO PATRIOTISMO CONSTITUCIONAL EM HABERMAS E MÜLLER COMO SOLUÇÃO DE COESÃO SOCIAL EM SOCIEDADES MULTICULTURAIS E DEMOCRÁTICAS

independente das diferenças étnicas, socioeconômicas, religiosas, etc. O pertencimento a uma Constituição que garante direitos e liberdades deveria promover esta integração multicultural. ${ }^{24}$

O próprio Müller assevera que esta reflexão não deixa de ser, em certa maneira, uma forma de universalização do modo constitucional americano de entender a realidade, no sentido de garantir todas as diferenças culturais e étnicas desde que atreladas e incluídas na dinâmica de respeito constitucional. Desde os documentos fundadores dos Estados Unidos da América se observa esta busca por se construir uma terra de liberdade para todos, para além das divergências, uma nação para todas as nações, desde que enquadradas nos limites constitucionais. ${ }^{25}$

Já aqui se antevê na Constituição esta dupla premissa, de um lado a de exercer a função de coesão social que antes era prerrogativa do espírito nacional ou consciência social, e de outro de promover a integração das diferenças a partir do respeito aos direitos civis e liberdades individuais. ${ }^{26}$

A visão de Habermas enfatiza que em sociedades nas quais o nacionalismo é passível de criticismo há a tendência de as pessoas se reconhecerem em perfis identitários mais abstratos e reflexivos, ligados a estilos de vida, ideologias, camadas sociais. Desse modo também a noção de patriotismo precisa ser atualizada para uma dimensão mais abstrata e discursiva. A noção habermasiana ${ }^{27}$ de patriotismo constitucional, diferente daquele de Sternberg, é muito mais universalizante, e tende a esvaziar o direcionamento estatalista e nacionalista do conceito de patriotismo. 0 Estado deixa de ser uma entidade quase metafísica acima da sociedade para ser visto como uma instituição formada a partir de normas, sobretudo constitucionais, visando fomentar o surgimento da esfera pública como espaço em que os cidadãos exercem a própria racionalidade discursiva. ${ }^{28}$

Müller assinala que o patriotismo constitucional possui inclusive potencial de abertura ao diálogo com outras culturas constitucionais, possibilitando sua atualização a cenários de

${ }^{24}$ MÜLLER, Jan-Werner. Constitutional Patriotism. New Jersey: Princeton University Press, 2007. p. 2629.

${ }^{25}$ MÜLLER, Jan-Werner. Constitutional Patriotism. New Jersey: Princeton University Press, 2007. p. 32.

${ }^{26}$ Ibidem.

27 Para aprofundamentos sobre a visão de Habermas consultar: Habermas, Jürgen. Citizenship and National Identity: Some reflections on the future of Europe, 1992, 12(1) Praxis international; Habermas, Jürgen. The European Nation-State and the Pressures of Globalization, 1999, New Left Review 46; HABERMAS, Jürgen. Constitutional Democracy: A Paradoxical Union of Contradictory Principles?, 2001, 29(6), Political Theory 766; HABERMAS, Jürgen. A constelação pós-nacional: ensaios políticos. São Paulo: Littera Mundi, 2001.

${ }^{28}$ MÜLLER, Jan-Werner. Constitutional Patriotism. New Jersey: Princeton University Press, 2007. p. 30. 
ISSN 1981-3694

(DOI): $10.5902 / 1981369441312$

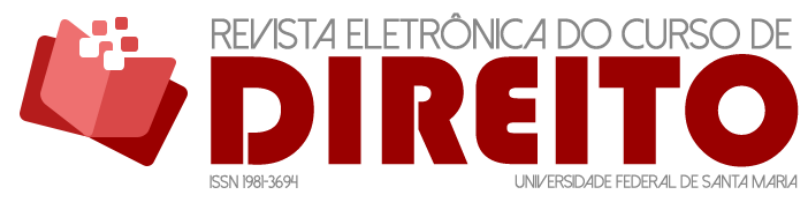

A PROPOSTA DO PATRIOTISMO CONSTITUCIONAL EM HABERMAS E MÜLLER COMO SOLUÇÃO DE COESÃO SOCIAL EM SOCIEDADES MULTICULTURAIS E DEMOCRÁTICAS

normas transnacionalmente estabelecidas. Isto porque o patriotismo constitucional possui a capacidade de se autonomizar dos limites nacionais e estatalistas.

Patriotismo constitucional não é nem tentativa de reforço do nacionalismo estatalista nem uma espécie de 'religião civil', como abordam argumentos opositores, mas busca identificar o conjunto de crenças, valores e disposições requeridas dos cidadãos a fim de se manter determinada regulamentação política. De certo modo, o patriotismo constitucional almeja responder a seguinte pergunta: 'como esperamos viver juntos? ${ }^{29}$ ' Isto depende do impulso que deve mover cada cidadão a reconhecer os demais como livres e iguais. ${ }^{30}$

Em sociedades multiculturais este nível de consenso pode ocorrer em torno da Constituição enquanto espaço de diálogo público e garantia de direitos básicos e liberdades individuais. Isto não significa que cada cidadão não possa discordar ou questionar normas específicas da Constituição, pois isto significaria supressão da liberdade individual de expressão, mas que apesar das discordâncias o sujeito reconhece à Constituição autoridade de representar o consenso estabelecido em dada comunidade política. ${ }^{31}$

Müller se defende das objeções nacionalistas e cosmpolitanistas ${ }^{32}$ contra o patriotismo constitucional, pois este seria a atitude de vínculo dos cidadãos às normas, valores e procedimentos constitucionais que resguardam uma sociedade democrática governada pelas leis. Desse modo o patriotismo constitucional não é nem nacionalista, pois se reconhecer na Constituição não passa por pertencer a uma etnia ou ideia de nação, e nem sequer cosmopolitanista, porque tampouco prega vínculo a valores transcendentais e globais. ${ }^{33}$

Dentro do patriotismo constitucional há abertura a grupos minoritários criticarem e reivindicarem mudanças no sistema de regras, a partir do momento em que se respeita a ordem jurídica e constitucional.

\footnotetext{
${ }^{29}$ Mocoroa faz importante estudo sobre o patriotismo constitucional aplicado às realidades latinoamericanas. MOCOROA, ¿Juan. Somos prisioneros de nuestra Identidad? Minorías culturales, Republicanismo y Constitucionalismo Democrático. Problema. Anuario de Filosofía y Teoría del Derecho, núm. 10, janeiro-dezembro de 2016, pp. 193-243.México, Cidade do México.

${ }^{30}$ MÜLLER, Jan-Werner. Constitutional Patriotism. New Jersey: Princeton University Press, 2007. p. 49.

31 Ibidem. p. 52-55.

32 Müller possui importante estudo sobre as implicações do patriotismo constitucional no cenário europeu, de como a União Europeia vem recebendo influências do patriotismo constitucional visando uma ordem jurídica constitucional comum: MÜLLER, Jan-Werner. Is Europe Converging on Constitutional Patriotism? Disponível em: https://www.princeton.edu/ jmueller/CRISPP\%20-\%20A\%20European\%20Convergence\%20on\%20Constitutional\%20Patriotis.pdf

33 MÜLLER, Jan-Werner. Three Objections to Constitutional Patriotism. Disponível em: http://www.princeton.edu/ jmueller/Constellations-CP-Three\%200bjections-JWMueller-May2006.pdf; MÜLLER, Jan-Werner. Seven ways to misunderstand Constitutional Patriotism, Politeia, XXV, 96, 2009.
} 
O objetivo da noção de patriotismo constitucional parece ser o de criação de uma cultura constitucional na qual os membros nutrem atitudes de disposição a respeito e valorização dos princípios da ordem constitucional. 0 patriotismo constitucional, dessa forma, tende a fomentar espaço de favorecimento ao próprio constitucionalismo. Isto é, a ordem jurídica pautada na Constituição, com leis e instituições sendo constantemente reinterpretadas conforme a Constituição exige uma cultura constitucional, e para isto antes uma atitude distribuída entre as pessoas de se sentirem vinculados à Constituição. Em Breda se encontra esta importante definição de patriotismo constitucional como uma teoria política que decorre da necessidade de as constituições modernas serem democraticamente abertas à pluralidade, exigindo práticas que movam as pessoas a buscarem determinado espírito coletivo, para além das fragmentações internas. Desse modo o patriotismo constitucional lida sempre com a dupla tensão: de um lado buscar a coesão social, de outro manter as liberdades individuais e direitos básicos. A dupla pretensão parece ser possível de realização mediante a construção efetiva de um patriotismo direcionado a uma cultura constitucional. ${ }^{34}$

Por isto na parte final deste trabalho abre-se a dimensão do reconhecimento. 0 patriotismo constitucional, para ser bem sucedido, exige a dialética do reconhecimento, na qual os indivíduos reconhecem-se mutuamente como membros efetivos de uma cultura constitucional. A ênfase está na abordagem hegeliana, importante fundamento para os estudos sobre dialética do reconhecimento, com a devida contribuição de Honneth ${ }^{35}$, discípulo e estudioso do pensamento de Habermas, e que atualiza a abordagem de Hegel para a realidade contemporânea.

\section{RECONHECIMENTO E PATRIOTISMO CONSTITUCIONAL}

Como abordado no tópico anterior percebeu-se que a teoria do patriotismo constitucional possui importantes raízes no pensamento de Habermas, mas este, como salientado pelo próprio aluno e seguidor Honneth, vincula-se a uma tradição kantiana, centrada, sobretudo, na dimensão epistemológica. Talvez por isto o modelo de patriotismo constitucional pareça insuficiente se não acompanhado por uma ideia de dialética do reconhecimento, pois a disposição a respeitar e valorizar a Constituição como instrumento de unidade social não nasce

${ }^{34}$ BREDA, Vito. Constitutional Patriotism: a Reasonable Theory of Radical Democracy? In: Selected Works of Vito Breda. Disponível em: https://works.bepress.com/vito_breda/1/

${ }^{35} \mathrm{HONNETH}$, Axel. A luta por reconhecimento: a gramática moral dos conflitos sociais. São Paulo: Ed. 34, 2003. 
ISSN 1981-3694

(DOI): $10.5902 / 1981369441312$

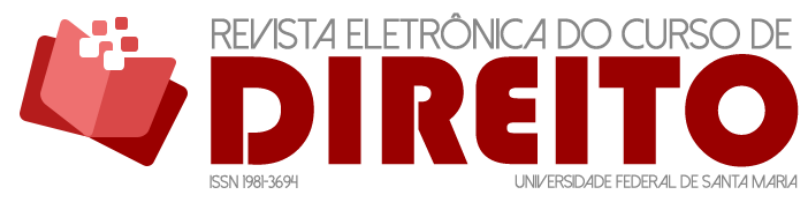

A PROPOSTA DO PATRIOTISMO CONSTITUCIONAL EM HABERMAS E MÜLLER COMO SOLUÇÃO DE COESÃO SOCIAL EM SOCIEDADES MULTICULTURAIS E DEMOCRÁTICAS

da espontaneidade das pessoas e grupos ou de imposições jurídicas, mas de movimentos intersubjetivos e dialéticos a partir dos quais indivíduos de culturas, etnias e ideologias distintas se reconhecem mutuamente como iguais e livres atores de construção social. Daí ser necessário retomar a visão hegeliana, também estudada por Habermas, para preencher certa lacuna do patriotismo constitucional: a dialética do reconhecimento como condição epistemológica para a efetividade do patriotismo constitucional.

Pode-se dizer que numa abordagem hegeliana o Direito surge como fenomenologia porque é emanado pelos costumes e valores reconhecidos por determinada Sociedade. As normas e instituições jurídicas não são regras absolutas, mas resultados do percurso histórico. 0 movimento de negação das regras e instituições, entretanto, permitiria visualizar a Ideia que as faz movimentar, ou seja, a própria lógica jurídica que subsistiria subterraneamente ao movimento concreto do Direito. O Direito, assim, nasce sempre das dialéticas históricas de reconhecimento em determinada sociedade.

Este movimento começa com a dialética por reconhecimento, explorada na obra Fenomenologia do Espírito. A proposta nesta seção é demonstrar que o patriotismo constitucional exige internamente a dialética do reconhecimento para que seja efetivo.

A dialética do reconhecimento se inicia com a consciência buscando o Outro para realizar a própria afirmação. Mas ao realizar tal movimento a consciência de si perceberá que o Outro faz o mesmo esforço em relação a ela. ${ }^{36}$ Ambas as consciências saem de si para reconhecer o Outro, e neste processo ambas se reconhecerão como a si mesmas. Ao buscar o Outro para satisfazer o meu desejo e perceber que o Outro faz o mesmo movimento se medeia a dialética de reconhecimento, em que ambas as consciências eliminam a desigualdade entre elas. Tal movimento, para Hegel, possui dupla significação:

Para a consciência-de-si há uma outra consciência-de-si [ou seja]: ela veio para fora de si. Isso tem dupla significação: primeiro, ela perdeu a si mesma, pois se acha numa outra essência. Segundo, com isso ela suspendeu o Outro, pois não vê o Outro como essência, mas é a si mesma que vê no Outro. ${ }^{37}$

\footnotetext{
${ }^{36}$ SOARES, Josemar. Direito, Consciência e Sociedade. São Paulo: Intelecto, 2018.

37 "Es ist für das Selbstbewußtsein ein anderes Selbstbewußtseins; es ist außer sich gekommen. Die hat die gedoppelte Bedeutung: erstlich, es hat sich selbst verloren, denn es findet sich als ein anderes Wesen; zweitens, es hat damit das Andere aufgehoben, denn es sieht auch nicht das andere als Wesen, sondern sich selbst im anderen". HEGEL, G. W. F. Phänomenologie des Geistes. Frankfurt am Main: Suhrkamp, 1986 (Werke in zwanzig Bänden, 3) auf der Grundlage der Werke von 1832-1845 neu edierte Ausgabe, Redaktion Eva Moldenhauer und Karl Markus Michel. p. 274.

HW 3, p. 274.
} 
Em outras palavras, a consciência, para reconhecer o Outro, precisou suspender ${ }^{38}$ a si mesma, passando a ter o Outro como essencial e a si como inessencial. Por outro lado, ela medeia o Outro para si. Ou seja, ao mesmo tempo em que suspende a si vê a si no Outro. E o Outro realiza o mesmo movimento nela. Duplo movimento de relativização de si, mas que ao mesmo tempo mantém o dado originário da busca por satisfação de si. Não se trata nem de absolutizar a si e nem de absolutizar o Outro, ou, para empregar termo especificamente hegeliano, nem finitizar-se em si e nem finitizar-se no Outro.

É desse movimento que, para Hegel, nasce a ideia de Para-Nós ${ }^{39}$, uma figura universal em que as consciências reconhecem-se reciprocamente como iguais. É somente no Para-Nós que sujeitos coletivos ou universais (como a sociedade) possuem validade e presença. Tal ideia será aprofundada adiante por meio do conceito de Eticidade.

Mas o desejo não se finitiza no reconhecimento. Após reconhecer e ser reconhecida por Outro a consciência buscará a afirmação de si diante deste Outro. 0 resultado é uma luta ${ }^{40}$ que as coloca entre a vida e a morte. Aquela consciência que teve coragem para arriscar tudo de si torna-se senhor, enquanto a outra, que se abalou diante da possibilidade do fim da existência, finitizou em si mesma e na vida, e tornou-se escravo.

A luta por reconhecimento, mais que plano natural é a luta na dimensão existencial, a luta por reconhecimento que movimenta o desejo de cada ser humano de ser reconhecido. A partir da dialética do reconhecimento, da pluralidade de Eu se forma o Nós. A dimensão da luta

\footnotetext{
380 termo 'suspender' seria uma tradução aproximativa do alemão 'aufhebung', que em Hegel possui uma significação bastante precisa, pois filosoficamente identifica o movimento de superação de um dado anterior, mas conservando-o, isto é, atualizando-o. Suspender, então, é negar o dado sem eliminá-lo. 0 novo dado conserva o anterior e o atualiza. A tradução por 'atualização' também não seria precisa, pois não assinalaria o aspecto negativo e fundamental.

39 HEGEL, G. W. F. Phänomenologie des Geistes. Frankfurt am Main: Suhrkamp, 1986 (Werke in zwanzig Bänden, 3) auf der Grundlage der Werke von 1832-1845 neu edierte Ausgabe, Redaktion Eva Moldenhauer und Karl Markus Michel.p. 125.

40 Em importante texto do período da juventude intitulado Da Positividade da Religião Cristã Hegel formulava o Amor (Liebe) como fundamento para a vida ética, que depois na Fenomenologia do Espírito, primeira obra da fase intelectual madura seria substituído pela ideia de Luta. Ainda assim o Amor constituirá elemento essencial para construção do sistema da Eticidade nas Linhas Fundamentais da Filosofia do Direito, vez que é a base da instituição da Família. É certo que a passagem do Amor para a Luta é uma das questões que intriga e estimula estudos hegelianos até hoje. A Luta não pode ser entendida como superação do Amor, mas como nova forma de estabelecer vínculos éticos. A Luta manifesta, mais que o Amor, a condição dialética do conflito, vez que põe duas consciências a se desafiarem. Pode-se dizer que o Amor está presente na dialética do reconhecimento, mas o Amor apenas em si mesmo é insuficiente para as relações sociais, pois a existência de conflitos é inevitável. 0 problema não é falsear uma inexistência de conflitos, mas aprender a superá-los e não finitizar-se neles. E esta passagem existencial é proporcionada apenas pela fenomenologia da luta. Em síntese não cabe afastar o amor, mas atualizá-lo na dialética do reconhecimento. Para o texto Da Positividade da Religião Cristã: HEGEL, G. W. F. Escritos de juventud. México: Fondo de Cultura Econômica, 1978.
} 
ISSN 1981-3694

(DOI): $10.5902 / 1981369441312$

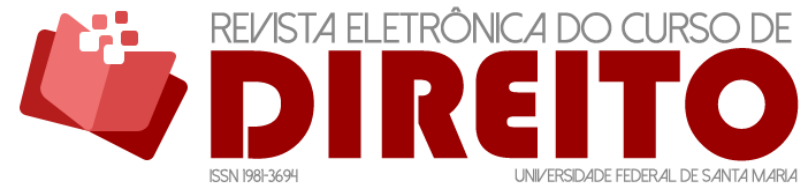

A PROPOSTA DO PATRIOTISMO CONSTITUCIONAL EM HABERMAS E MÜLLER COMO SOLUÇÃO DE COESÃO SOCIAL EM SOCIEDADES MULTICULTURAIS E DEMOCRÁTICAS

representa elemento central nas dialéticas modernas e contemporâneas, pois sintetiza a busca de pessoas e grupos de serem reconhecidas em suas especificidades. Minorias étnicas, religiosas, enquanto condições sociais e de orientação de vida conquistaram direitos lutando por suas identidades, pelo reconhecimento da própria dignidade. A luta por reconhecimento demonstra que mesmo na busca por igualdade há sempre o elemento da tentativa de se autoafirmar também como único. 0 patriotismo constitucional lida com esta dinâmica, porque ao mesmo tempo em que realiza a igualdade diante da Constituição, oferece a diversidade das realidades minoritárias no interior da população. A igualdade abstrata não promove coesão social, porque a igualdade deve se dar conta das diferenças internas de cada multiplicidade de pessoas e grupos que se busca identificar em determinada Constituição.

Observa-se agora abordagem conferida na obra Linhas Fundamentais da Filosofia do Direito.

Hegel $^{41}$ inicia a exposição da Eticidade no § 142:

A eticidade é a ideia da liberdade, enquanto Bem vivente, que tem na autoconsciência seu saber, seu querer, e pelo agir dessa, sua efetividade, assim como essa tem, no ser ético, seu fundamento sendo em si e para si e seu fim motor, - [a eticidade é] o conceito da liberdade que se tornou mundo presente $e$ natureza da autoconsciência.

A eticidade resultada do saber e do querer da consciência de si, depois de superar diversos momentos, a se iniciar pela dialética do reconhecimento. A eticidade é o conceito da liberdade que se tornou mundo presente e natureza da consciência de si, isto é, a própria ideia de Liberdade realizada, de que de tal forma se tornou uma segunda natureza da consciência de si. $^{42}$

O ser ético, dessa forma, não é externo e coercitivo à consciência, mas seu próprio conteúdo, de tal forma que as instituições e leis que derivarem daquela comunidade e Estado não são opressoras contra seus membros, mas a manifestação da vontade dos indivíduos. O ser ético deve se refletir na Constituição, de tal modo que o respeito aos valores e princípios constitucionais represente exercício da própria liberdade. Desse modo a Constituição se torna expressão viva da vontade que anima os movimentos de uma pluralidade de pessoas e grupos.

\footnotetext{
${ }^{41}$ HEGEL, G. W. F. Grundlinien der Philosophie des Rechts oder Naturrecht und Staatswissenschaft im Grundrisse. Frankfurt am Main: Suhrkamp, 1982 (Werke in zwanzig Bänden 7) [mit Hegels eigenhändigen Notizen und den mündlichen Zusätzen], auf der Grundlage der Werke von 1832-1845 neu edierte Ausgabe Redaktion Eva Moldenhauer und Karl Markus Michel. p. 292.

42 HEGEL, G. W. F. Grundlinien der Philosophie des Rechts oder Naturrecht und Staatswissenschaft im Grundrisse. Frankfurt am Main: Suhrkamp, 1982 (Werke in zwanzig Bänden 7) [mit Hegels eigenhändigen Notizen und den mündlichen Zusätzen], auf der Grundlage der Werke von 1832-1845 neu edierte Ausgabe Redaktion Eva Moldenhauer und Karl Markus Michel.
} 
A realidade da eticidade é harmônica e dialético, também em sua dimensão conflituosa, pois nela uma série de interesses (família, sociedade civil, Estado, indivíduo, etc.) coexistem. Cada fração da sociedade, no entanto, não busca eliminação das demais, mas a própria afirmação de identidade. As frações querem ser iguais diante da Constituição mas diversas na própria identidade enquanto parte de uma totalidade.

A eticidade seria aquele momento de convivência social onde os indivíduos sabem ser membros efetivos de uma totalidade maior, seja ela o Estado ou a comunidade em geral, e respeita a Constituição e as normas emanadas pelo Poder Público não por atitude de obrigação, mas por vontade livre. ${ }^{43}$

Por outro lado, a substância ética, suas leis e suas potências, não passam, para o sujeito, como algo de estranho, mas, tem o testemunho de constituir em si mesma sua própria essência, onde tem o seu sentimento e nele vive como um elemento não diferente de si. Trata-se de uma relação imediata, que é mais idêntica que na fé e na confiança. ${ }^{44}$

Entretanto, mais importante que o respeito em si às instituições e normas, que parecem ser mais efeito que causa, é o processo de reconhecimento mútuo, já realizado pelas consciências de si. 0 indivíduo não agride o outro e as instituições porque reconhece o outro e as instituiç̧̃es como ele próprio, pois todos são membros de uma totalidade orgânica, logo agredir o outro é agredir a si mesmo. ${ }^{45}$

$\mathrm{Na}$ dialética do reconhecimento hegeliana a consciência precisa sair de si e reconhecer o outro como a si mesmo. Hegel substituiu o amor pela luta/conflito, portanto não se trata de exigir das pessoas o amor, o sentimento genuíno pela humanidade, mas apenas um sentimento de respeito mútuo pelo outro, de reconhecimento de seu valor e humanidade, de entender que o outro é igual a ele mesmo, então ambos membros de um mesmo projeto social maior. Amor seria uma etapa ainda mais evoluída desse processo.

0 que se coloca em questão é se uma consciência que não reconhece o outro pode reconhecer a si mesma. Como afirmava Hegel, reconhecimento é necessariamente mútuo. Ser pessoa implica em ser reconhecido por outros como pessoa, da mesma forma que ser

\footnotetext{
${ }^{43}$ HEGEL, G. W. F. Grundlinien der Philosophie des Rechts oder Naturrecht und Staatswissenschaft im Grundrisse. Frankfurt am Main: Suhrkamp, 1982 (Werke in zwanzig Bänden 7) [mit Hegels eigenhändigen Notizen und den mündlichen Zusätzen], auf der Grundlage der Werke von 1832-1845 neu edierte Ausgabe Redaktion Eva Moldenhauer und Karl Markus Michel.

${ }^{44}$ HEGEL, G. W. F. Grundlinien der Philosophie des Rechts oder Naturrecht und Staatswissenschaft im Grundrisse. Frankfurt am Main: Suhrkamp, 1982 (Werke in zwanzig Bänden 7) [mit Hegels eigenhändigen Notizen und den mündlichen Zusätzen], auf der Grundlage der Werke von 1832-1845 neu edierte Ausgabe Redaktion Eva Moldenhauer und Karl Markus Michel. p. 295.

45 SOARES, Josemar. Filosofia do Direito. Curitiba: IESDE, 2019.
} 
ISSN 1981-3694

(DOI): $10.5902 / 1981369441312$

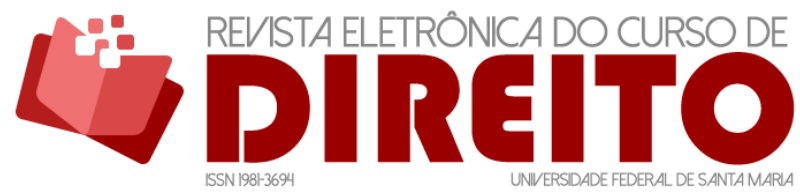

A PROPOSTA DO PATRIOTISMO CONSTITUCIONAL EM HABERMAS E MÜLLER COMO SOLUÇÃO DE COESÃO SOCIAL EM SOCIEDADES MULTICULTURAIS E DEMOCRÁTICAS

proprietário de um bem implica em reconhecer o outro também como proprietário de um bem. Não há real dicotomia entre direitos e deveres. Exercer o direito responsabiliza o sujeito no dever de respeitar o direito alheio. ${ }^{46}$

Retomando o argumento do patriotismo constitucional, este, para ser bem sucedido, precisa que a dialética do reconhecimento seja feita visando a cultura constitucional. Para Hegel a Constituição expressa a totalidade surgida como unidade, que contém em si a pluralidade de forças no interior da sociedade. É pela Constituição que fragmentações sociais, étnicas, ideológicas, econômicas, culturais, se tornam uma unidade distinguível de outras sociedades. É pela Constituição, ainda, que esta pluralidade se faz presença viva, porque ali possui direito a voto, a manifestação, a proposição de idéias. A Constituição, de um lado cria a unidade, de outro mantém a pluralidade e este duplo escopo precisa sempre ser atualizado pelo patriotismo constitucional.

O patriotismo constitucional não pode perder de vista, deste modo, a dialética do reconhecimento, pois como assinalaria Honneth ${ }^{47}$, o direito nasce da luta por reconhecimento, da luta de pessoas e grupos a serem reconhecidos como membros efetivos de uma sociedade organizada, na qual exercem direitos e deveres. Este reconhecimento, salienta Honneth, não pode ser apenas jurídico (formal, estabelecido nas leis e na Constituição), mas também moral (aberto às individualidades) e ético, facilitando a inserção das diversidades na ordem jurídica com respeito à própria dignidade. Esta dimensão ética do reconhecimento seria incumbência de uma pedagogia visando cultura constitucional, ou, em outras palavras, do patriotismo constitucional.

A força da Constituição depende de os membros se reconhecerem nela, e para isto devem antes realizar o movimento de sair de si e reconhecer os outros indivíduos como iguais e livres membros da mesma sociedade. Em comunidades multiculturais e democráticas isto implica o reconhecer pessoas de grupos étnicos, culturais, sociais distintos. Apesar das diferenças reconhecem-se como iguais portadores de direitos e deveres diante da Constituição.

A luta por reconhecimento, como salienta Honneth, ocorre porque as partes de uma sociedade querem ser reconhecidas pela própria sociedade. Isto é, elas respeitam a sociedade, querem integrar a sociedade, mas querem integrar à sua maneira. Desse modo encontra-se área de convergência entre a teoria do reconhecimento hegeliana e a proposta de

${ }^{46}$ HEGEL, G. W. F. Phänomenologie des Geistes. Frankfurt am Main: Suhrkamp, 1986 (Werke in zwanzig Bänden, 3) auf der Grundlage der Werke von 1832-1845 neu edierte Ausgabe, Redaktion Eva Moldenhauer und Karl Markus Michel.

${ }^{47}$ HONNETH, Axel. A luta por reconhecimento: a gramática moral dos conflitos sociais. São Paulo: Ed. 34, 2003. 
patriotismo constitucional, pois este último busca a coesão social, fazer uma pluralidade de pessoas e grupos querer viver em harmonia, mesmo com suas diferenças. Isto implica o reconhecimento pela igualdade de um lado e a luta por se autoafirmar de outro. A partir de Hegel e Honneth pode-se, então, contribuir para uma condição epistemológica de efetividade na proposta de patriotismo constitucional, a partir das concepções de Habermas e Müller, já que com a busca por reconhecimento se adentra a temática viva do Eu que é Nós e do Nós que é Eu, do querer se reconhecer no Todo sem perder a própria identidade. Ora, este é justamente a busca das democracias contemporâneas, abrir a diversidade, disponibilizar a cada pessoa e grupo afirmar a própria identidade, mas todos respeitando os valores e princípios constitucionais. A partir da Constituição as diferenças são incluídas em prol do projeto universal.

\section{CONCLUSÃO}

A realização da coesão social na contemporaneidade passa pela dialética de reconhecimento entre indivíduos que veem a si mesmos e ao outro como portantes de direitos e deveres, sendo assim corresponsáveis pela eticidade comunitária, representada pelos valores e princípios constitucionalmente garantidos.

Isto porque na contemporaneidade a crítica individual contra as instituições, leis e costumes que configuram dada sociedade é sempre mais acentuada, dificultando a permanência e consolidação de uma coesão social. A coesão social historicamente dependeu da tradição, mas se esta tradição vive ininterruptamente sob ataques críticos internos (pelos próprios membros) e externos (por outras comunidades) encontrará sempre dificuldade para se estabilizar.

É certo que exigir da contemporaneidade a suspensão deste modo crítico individualista permanente seria infrutífero e mesmo contraditório, vez que isto parece ser cada vez mais integrante do ethos contemporâneo. A facilidade de comunicação em dimensão global aproxima tanto pessoas, grupos e instituições que modelos comportamentais passam a ser, continuamente, objetos de críticas.

A convergência dos membros em referência ao Todo deve passar, portanto, de um lado pela busca de um critério que garanta unidade e por outro da manutenção do respeito às liberdades individuais. As constituições modernas visam este duplo objetivo, daí que a valorização até mesmo patriótica da Constituição se revela como instrumento possivelmente efetivo diante desta demanda. 
ISSN 1981-3694

(DOI): $10.5902 / 1981369441312$

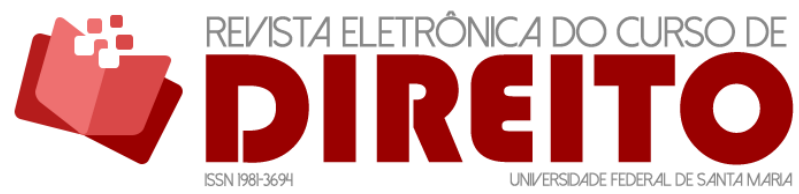

A PROPOSTA DO PATRIOTISMO CONSTITUCIONAL EM HABERMAS E MÜLLER COMO SOLUÇÃO DE COESÃO SOCIAL EM SOCIEDADES MULTICULTURAIS E DEMOCRÁTICAS

Aqui abre-se estrada para constituição de uma comunidade ética centrada na ideia de dignidade humana, uma comunidade ética que depende da efetivação da dialética de reconhecimento entre sujeitos que veem a si e ao outro como portadores de dignidade.

$\mathrm{Na}$ medida em as experiências totalitárias na II Guerra Mundial colocam em xeque a ideia de nacionalismo como estímulo à unidade social passa a ser necessário buscar outro critério realizador de coesão social. Analisando historicamente as Constituições modernas observa-se que estas buscam refletir não uma identidade étnica ou nacional, mas valores que norteariam o consenso de dada comunidade que embora possua a própria história é sempre aberta à chegada de novos grupos e membros.

No entanto a Constituição, para não ser apenas direito abstrato, em linguagem hegeliana, para que seja vivenciada pelos indivíduos e vista como necessária para manutenção da ordem jurídica e estabilidade das relações sociais, exige profunda dialética de reconhecimento entre seus membros. Daí ser necessário trabalho de pedagogia social, de enfatização do respeito aos valores e princípios constitucionais em todas as camadas da sociedade.

A inusitada expressão patriotismo constitucional busca expressar a necessidade de criar um espírito de disposição a agir em prol da Constituição, tendo em vista a solidariedade diante da comunidade em qual se reside e se constrói a própria dignidade de vida. 0 patriotismo constitucional, deste modo, não é abstração universalizante, porque se limita a valorizar os ditames de determinada Constituição, nem nacionalismo repaginado, porque se abre à diversidade étnica, ideológica, cultural, surge já imbuído do espírito democrático e multicultural que marca os ambientes temporais e espaciais desde o pós-Guerra.

Em sociedades multiculturais e democráticas a coesão social pode ser resguardada a partir do respeito à Constituição, por meio de uma disposição que bem poderia ser chamada patriotismo constitucional, por meio da qual cada membro se disponibiliza a exercer direitos e deveres não referente a uma nacionalidade, etnia ou grupo, mas a uma Constituição. Somente o constitucionalismo hoje parece capaz de proteger tanto a unidade social como a abertura e proteção das liberdades individuais e direitos básicos em sociedades marcadas pela diferenciação interna, nas quais as migrações transnacionais e outros fenômenos criam comunidades profundamente plurais em seu interior. 0 constitucionalismo une a todos em suas diferenças, criando uma unidade na pluralidade.

A primeira parte do artigo apresentou o desafio que representa o multiculturalismo em sociedades democráticas para a coesão social. A segunda sintetiza a proposta do patriotismo 
ISSN 1981-3694

(DOI): $10.5902 / 1981369441312$

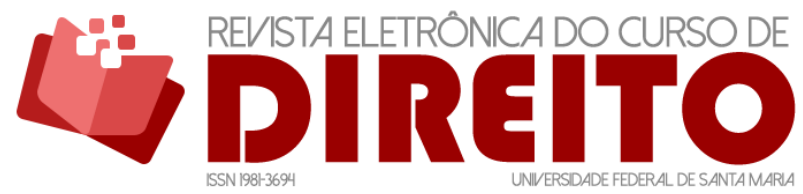

A PROPOSTA DO PATRIOTISMO CONSTITUCIONAL EM HABERMAS E MÜLLER COMO SOLUÇÃO DE COESÃO SOCIAL EM SOCIEDADES MULTICULTURAIS E DEMOCRÁTICAS

constitucional como solução a esta problemática. E a terceira parte enfatiza que o patriotismo constitucional, para ser efetivo, depende da condição epistemológica da dialética do reconhecimento, pois é esta que faz com que cada membro reconheça-se na Constituição e reconheça o outro como igual portador de direitos e deveres diante da Constituição, para além das divergências étnicas, culturais, ideológicas, etc.

\section{REFERÊNCIAS}

BENHABIB, Seyla. The rights of others: aliens, residents and citizens. Cambridge: Cambridge University Press, 2004.

BREDA, Vito. Constitutional Patriotism: a Reasonable Theory of Radical Democracy? In:

Selected Works of Vito Breda. Disponível em: https://works.bepress.com/vito_breda/1/

BUBER, Martin. Eu e Tu. São Paulo: Centauro, 2001.

CADEMARTORI, Sergio; CADEMARTORI, Daniela. Da tradição ocidental de constitucionalismo ao novo constitucionalismo latino-americano: análise das garantias constitucionais, Revista Novos Estudos Jurídicos, v. 19, n.3, p. 1014-1044.

COMIN, Lidiane Cássia; PAULI, Jandir. The meaning of work, organizational socialization and work context: the perspective of migrant workers, Revista de Administração Mackenzie, v. 19, 2018.

CRUZ, Paulo Márcio; PASOLD, César Luiz; FERRER, Gabriel Real. Reflexões sobre o futuro do Estado constitucional moderno, Revista Brasileira de Políticas Públicas, v. 6, p. 22-38, 2016.

GOZZI, Gustavo. Diritti e Civiltà. Bologna: Il Mulino, 2010.

HABERMAS, Jürgen. A constelação pós-nacional: ensaios políticos. São Paulo: Littera Mundi, 2001.

HABERMAS, Jürgen. Citizenship and National Identity: Some reflections on the future of Europe, 1992, 12(1) Praxis international.

HABERMAS, Jürgen. Constitutional Democracy: A Paradoxical Union of Contradictory Principles? , 2001, 29(6), Political Theory 766

HABERMAS, Jürgen. The European Nation-State and the Pressures of Globalization, 1999, New Left Review 46.

HEGEL, G. W. F. Escritos de juventud. México: Fondo de Cultura Econômica, 1978. 
HEGEL, G. W. F. Fenomenologia do Espírito. Tradução de Paulo Meneses. Petrópolis: Vozes, 2005.

HEGEL. G W. F. Filosofia do Direito. Tradução de Paulo Meneses. São Leopoldo: Ed. da UNISINOS, 2010.

HEGEL, Georg W. F. Grundlinien der Philosophie des Rechts oder Naturrecht und Staatswissenschaft im Grundrisse. Frankfurt am Main: Suhrkamp, 1982 (Werke in zwanzig Bänden 7) [mit Hegels eigenhändigen Notizen und den mündlichen Zusätzen], auf der Grundlage der Werke von 1832-1845 neu edierte Ausgabe Redaktion Eva Moldenhauer und Karl Markus Michel.

HEGEL, Georg W. F. Phänomenologie des Geistes. Frankfurt am Main: Suhrkamp, 1986 (Werke in zwanzig Bänden, 3) auf der Grundlage der Werke von 1832-1845 neu edierte Ausgabe, Redaktion Eva Moldenhauer und Karl Markus Michel.

HELLER, Hermann. Teoria do Estado. São Paulo: Mestre Jou, 1968.

HONNETH, Axel. Luta por reconhecimento: a gramática moral dos conflitos sociais. São Paulo: Editora 34, 2003.

KYMLICKA, Will. Multicultural citizenship. Oxford: Oxford Press, 1995.

LANZILLO, Maria Laura. II multiculturalismo. Bari: Laterza, 2005. p. VIII-IX.

LOCCHI, Maria Chiara. La questione del riconoscimento giuridico delle differenze culturali nelle società pluraliste: alcune considerazioni a partire dalla giurisprudenza sui rom della Corte Europea dei diritti dell'uomo, Revista Novos Estudos Jurídicos, v. 20, n.1, 2015.

MOCOROA, ¿Juan. Somos prisioneros de nuestra Identidad? Minorías culturales, Republicanismo y Constitucionalismo Democrático. Problema. Anuario de Filosofía y Teoría del Derecho, núm. 10, janeiro-dezembro de 2016, pp. 193-243.

MÜLLER, Jan-Werner. Constitutional Patriotism. New Jersey: Princeton University Press, 2007.

MÜLLER, Jan-Werner. Is Europe Converging on Constitutional Patriotism? Disponível em:

https://www.princeton.edu/ jmueller/CRISPP\%20--

\%20A\%20European\%20Convergence\%20on\%20Constitutional\%20Patriotis.pdf

MÜLLER, Jan-Werner. Seven ways to misunderstand Constitutional Patriotism, Politeia, XXV, 96, 2009.

MÜLLER, Jan-Werner. Three Objections to Constitutional Patriotism. Disponível em: http://www.princeton.edu/ jmueller/Constellations-CP-Three\%200bjections-JWMuellerMay2006.pdf

NORMAN, Wayne. Justice and Stability in multinational societies. In: GAGNON, Alain;

SMITH, Anthony. The ethnic origins of Nations. New Jersey: Wiley-Blackwell, 1991. 
PASOLD, Cesar Luiz. Metodologia da pesquisa jurídica: teoria e prática. Florianópolis: Conceito Editorial. 2015.

PILAU SOBRINHO, Liton Lanes; SIRIANNI, Guido; PIFFER, Carla. Migrações transnacionais e multiculturalismo: um desafio para a União Europeia, Revista Novos Estudos Jurídicos, v. 19, n. 4, 2014.

ROSANVALLON, Pierre. Counter-Democracy: Politics in a age of Distrust. Cambridge: Cambridge University Press, 2008.

SOARES, Josemar. Direito, Consciência e Sociedade. São Paulo: Intelecto, 2018.

SOARES, Josemar. Filosofia do Direito. Curitiba: IESDE, 2019.

TAYLOR, Charles. A Política de Reconhecimento. In: APPIAH, Anthony; TAYLOR, Charles. (Org.). Multiculturalismo: examinando a política de reconhecimento. Lisboa: Piaget, 1998.

TRUZZI, Oswaldo; MONSMA, Karl. Sociologia das migrações: entre a compreensão do passado e os desafios do presente, Revista Sociologias, ano 20, n. 49, 2018.

TULLY, James (Orgs.). Multinational Democracies. Cambridge: Cambridge University Press, 2001.

Recebido em: 25.11.2019 / Revisões requeridas em: 19.03.2020 / Aprovado em: 30.10.2020 / Publicado em: 22.04.2021

\section{COMO FAZER REFERÊNCIA AO ARTIGO (ABNT):}

SOARES, Josemar. A PROPOSTA DO PATRIOTISMO CONSTITUCIONAL EM HABERMAS E MÜLLER COMO SOLUÇÃOO DE COESÃO SOCIAL EM SOCIEDADES MULTICULTURAIS E DEMOCRÁTICAS. Revista Eletrônica do Curso de Direito da UFSM, Santa Maria, RS, v. 15, n. 3, 41312, set./dez. 2020. ISSN 1981-3694. DOI: http://dx.doi.org/10.5902/1981369441312.

Disponível em: https://periodicos.ufsm.br/revistadireito/article/view/41312 Acesso em: dia mês. ano.

Direitos autorais 2020 Revista Eletrônica do Curso de Direito da UFSM

Editores responsáveis: Rafael Santos de Oliveira e Angela Araujo da Silveira Espindola

Esta obra está licenciada com uma Licença Creative Commons Atribuição-NãoComercial-SemDerivações 4.0 Internacional.

\section{SOBRE O AUTOR}

\section{JOSEMAR SOARES}

Doutor em Filosofia pela Universidade Federal do Rio Grande do Sul (2009), Mestre em Ciência Jurídica pela Universidade do Vale do Itajaí (2003), Mestre em Educação pela Universidade Federal de Santa Maria (1999), especialista em Psicologia Social pela Universidade Estatal de São Petersburgo (Rússia). É professor dos cursos de Mestrado e Doutorado no Programa de PósGraduação Stricto Sensu em Ciência Jurídica da Universidade do Vale do Itajaí - UNIVALI. Como docente atua principalmente na linha de pesquisa Estado, Transnacionalidade e Sustentabilidade, vinculada à área de concentração Principiologia Constitucional e Política do Direito, do Programa de Pós-Graduação em Ciência Jurídica da UNIVALI. 